\title{
Range expansion of a fouling species indirectly impacts local species interactions (\#18935)
}

First revision

Please read the Important notes below, the Review guidance on page 2 and our Standout reviewing tips on page 3. When ready submit online. The manuscript starts on page 4.

Important notes

\section{Editor}

Tim Collins

Files

1 Tracked changes manuscript(s)

1 Rebuttal letter(s)

1 Figure file(s)

1 Table file(s)

3 Raw data file(s)

Please visit the overview page to download and review the files not included in this review PDF.

Declarations

Involves a field study on animals or plants. 
Please read in full before you begin

\section{How to review}

When ready submit your review online. The review form is divided into 5 sections. Please consider these when composing your review:

\section{BASIC REPORTING}

2. EXPERIMENTAL DESIGN

3. VALIDITY OF THE FINDINGS

4. General comments

5. Confidential notes to the editor

You can also annotate this PDF and upload it as part of your review

To finish, enter your editorial recommendation (accept, revise or reject) and submit.

\section{BASIC REPORTING}

Clear, unambiguous, professional English language used throughout.

Intro \& background to show context. Literature well referenced $\&$ relevant.

Structure conforms to PeerJ standards, discipline norm, or improved for clarity.

Figures are relevant, high quality, well labelled \& described.

Raw data supplied (see PeerJ policy).

\section{EXPERIMENTAL DESIGN}

Original primary research within Scope of the journal.

Research question well defined, relevant $\&$ meaningful. It is stated how the research fills an identified knowledge gap.

Rigorous investigation performed to a high technical \& ethical standard.

Methods described with sufficient detail \& information to replicate.

\section{VALIDITY OF THE FINDINGS}

Impact and novelty not assessed. Negative/inconclusive results accepted. Meaningful replication encouraged where rationale $\&$ benefit to literature is clearly stated.

Data is robust, statistically sound, $\&$ controlled.
Conclusions are well stated, linked to original research question \& limited to supporting results.

Speculation is welcome, but should be identified as such.

The above is the editorial criteria summary. To view in full visit https://peerj.com/about/editorialcriteria/ 
The best reviewers use these techniques

Tip

\author{
Support criticisms with \\ evidence from the text or from \\ other sources
}

\section{Give specific suggestions on how to improve the manuscript}

\section{Comment on language and grammar issues}

Organize by importance of the issues, and number your points

\section{Example}

Smith et al (J of Methodology, 2005, V3, pp 123) have shown that the analysis you use in Lines 241-250 is not the most appropriate for this situation. Please explain why you used this method.

Your introduction needs more detail. I suggest that you improve the description at lines 57- 86 to provide more justification for your study (specifically, you should expand upon the knowledge gap being filled).

The English language should be improved to ensure that your international audience can clearly understand your text. I suggest that you have a native English speaking colleague review your manuscript. Some examples where the language could be improved include lines 23, 77, 121, 128 - the current phrasing makes comprehension difficult.

1. Your most important issue

2. The next most important item

3. ...

4. The least important points

Line 56: Note that experimental data on sprawling animals needs to be updated. Line 66: Please consider exchanging "modern" with "cursorial".

I thank you for providing the raw data, however your supplemental files need more descriptive metadata identifiers to be useful to future readers. Although your results are compelling, the data analysis should be improved in the following ways: $A A, B B, C C$

I commend the authors for their extensive data set, compiled over many years of detailed fieldwork. In addition, the manuscript is clearly written in professional, unambiguous language. If there is a weakness, it is in the statistical analysis (as I have noted above) which should be improved upon before Acceptance.
Comment on strengths (as well as weaknesses) of the manuscript




\title{
Range expansion of a fouling species indirectly impacts local species interactions
}

\author{
Cori J Speights ${ }^{\text {Corresp., }}{ }^{1,2}$, Michael W McCoy ${ }^{2}$ \\ 1 Department of Biological Sciences, Mississippi State University, Starkville, Mississippi, United States \\ 2 Department of Biology, East Carolina University, Greenville, North Carolina, United States \\ Corresponding Author: Cori J Speights \\ Email address: cjs815@msstate.edu
}

We investigate how recent changes in the distribution and abundance of a fouling organism affect the strength of interactions between a commercially important foundation species and a common predator. Increases in the abundance of boring sponges that bioerode the calcified shells of oysters and other shelled organisms have been attributed to increased salinization of estuarine ecosystems. We test the hypothesis that fouling by boring sponges will change the interaction strength between oysters and a common predator (stone crabs). We generated five oyster density treatments crossed with two sponge treatments (sponge and no sponge). We contrasted the interaction strength between stone crabs and fouled and non-fouled oysters by comparing the parameters of fitted functional response curves based on Rogers random predation model. We found that fouled oysters suffered higher predation from stone crabs, and that the increased predation risk stemmed from a reduction in the handling time needed to consume the fouled oysters. These findings highlight the importance of understanding the effects of abiotic changes on both the composition of ecological communities, and on the strengths of direct and indirect interactions among species. Global climate change is altering local ecosystems in complex ways, and the success of restoration, management, and mitigation strategies for important species requires a better appreciation for how these effects cascade through ecosystems. 
1 Range expansion of a fouling species indirectly impacts local species interactions

2 Cori J. Speights ${ }^{1,2}$ and Michael W. McCoy ${ }^{2}$

$3{ }^{1}$ Department of Biological Sciences, Mississippi State University, Starkville, Mississippi, United

4 States

$5{ }^{2}$ Department of Biology, East Carolina University, Greenville, North Carolina, United States

6 cjs815@msstate.edu; mccoym@ecu.edu

$7 \quad$ Running Title: Indirect impacts of expansions on species

8 Corresponding author: Cori J. Speights ; cjs815@msstate.edu 
10

11

\section{Abstract}

We investigate how recent changes in the distribution and abundance of a fouling organism affect the strength of interactions between a commercially important foundation species and a common predator. Increases in the abundance of boring sponges that bioerode the calcified shells of oysters and other shelled organisms have been attributed to increased salinization of estuarine ecosystems. We test the hypothesis that fouling by boring sponges will change the interaction strength between oysters and a common predator (stone crabs). We generated five oyster density treatments crossed with two sponge treatments (sponge and no sponge). We contrasted the interaction strength between stone crabs and fouled and non-fouled oysters by comparing the parameters of fitted functional response curves based on Rogers random predation model. We found that fouled oysters suffered higher predation from stone crabs, and that the increased predation risk stemmed from a reduction in the handling time needed to consume the fouled oysters. These findings highlight the importance of understanding the effects of abiotic changes on both the composition of ecological communities, and on the strengths of direct and indirect interactions among species. Global climate change is altering local ecosystems in complex ways, and the success of restoration, management, and mitigation strategies for important species requires a better appreciation for how these effects cascade through ecosystems.

\section{Introduction}

The strength of interactions between predators and prey can be dependent upon ecological context and a plethora of environmental variables (Grabowski 2004; Laudien \& Wahl 1999; Menge 1995; Wahl et al. 1997). For example interactions with the abiotic environment (e.g. temperature, carbon dioxide, sea level rise) can change activity levels or physiological processes (Gilman et al. 2010), and the presence of other organisms can directly or indirectly 
33 change the strength of species interactions (Preisser et al. 2005; Werner \& Peacor 2003). For

34 example, Schmitt et al. (1983) showed that drill holes on kelp snails that were caused by failed octopus predation attempts resulted in increased barnacle fouling the snails shells that ultimately increased the snail's proximity and risk to benthic predators by increasing the amount of time spent on the benthos rather than on $\mathrm{k}$ Fouling organisms on marine mollusks can also increase susceptibility to predators by compromising the integrity of protective shells (Duckworth \& Peterson 2013). These indirect effects, where one species alters the strength of interactions between other species, may become more common and important as species invasions or range expansions resulting from environmental change lead to novel direct and indirect species interactions (Gilman et al. 2010; Kordas et al. 2011; Walther 2010). Sunday et al. 2016). Understanding how changes in biotic and abiotic conditions of ecosystems may change species interactions might be particularly important for foundation species and the communities that depend on their biogenic habitat structures (Hoegh-Guldberg et al. 2007). For example, oysters are foundation species in estuaries because their biogenically formed calcium carbonate shells provide habitat structure and refuge that support many other species (Gutiérrez et al. 2003). Oysters also provide services such as water filtration that reduces eutrophication,

52 and their reefs provide coastal protection (Meyer et al. 1997; Newell 2004; van Wesenbeeck et al. 2013). Therefore, changes in the distribution of predators or fouling species that affect the

54 health or survival of oysters can have important implications for both oysters and oyster reef 55 communities and the services they provide. 
In this study we investigated how the interactions between oysters and a common oyster

57 predator are influenced by a bioeroding sponge which may be expanding its distribution as a

result of increasing salinity and temperature in coastal estuaries (Hong \& Shen 2012; Lindquist 2011). Specifically, we investigated how the presence of boring sponges, Cliona spp., impact trophic interactions between eastern oysters, Crassostrea virginica, and an important native predator, the stone crab Menippe mercenaria. While studies have shown stone crabs can have less of an effect on oyster reefs than other mesopredators (e.g. mud crabs) they have recently increased establishment in North Carolina oyster reefs (Lindquist 2011; Rindone \& Eggleston 2011), and we still do not know the magnitude of their effects on oysters interacting with other species, such as sponges. Boring sponges bioerode the calcium carbonate substrates on which they settle (Duckworth \& Peterson 2013; Fang et al. 2013). Mollusks that are hosts to boring sponges have weakened shells (Stefaniak et al. 2005), slower growth, reduced condition, and lower survival than mollusks lacking these bioeroding colonists (Carroll et al. 2015). Therefore, we quantified the effects of boring sponges on the interaction strength between stone crabs and fouled and non-fouled oysters. We compared the shape of the crab's functional response to test the hypothesis that the weakened shells of fouled oysters caused by boring sponges will increase the strength of the predator-prey interaction. We focused on the functional response because it is the most direct measure of the interaction strength between predators and prey and it provides a mechanistic link to their population dynamics.

$$
\text { Specifically, to determine the effect of sponges on oyster survival we compared the }
$$
parameters of type II functional responses (i.e. changes in attack rates or handling times). If sponges are distasteful then crabs will be more likely to avoid foraging on fouled oysters and this affect will be manifested in differences in attack rates. In contrast, if sponges cause changes in 
79

80

81

82

83

84

85

86

87

88

shell strength that facilitate crab predation, then we might expect to see shorter handling times and thus higher maximum consumption rates by crabs on fouled oysters.

\section{Methods}

Stone crabs were collected from Middle Marsh in Beaufort, North Carolina (NCDMF Permit No. 706671) and allowed to acclimate in $0.6 \mathrm{~m}^{2}$ tanks at the Duke Marine lab for at least 48 hours. Each tank received a constant flow of unfiltered seawater and a piece of PVC pipe was provided for refuge. Ten crabs were each wet weighed $(\mathrm{g})$ and the length $(\mathrm{mm})$ of their carapace measured with digital calipers (mean \pm st. error: $93.6 \pm 10.9 \mathrm{~g}$ and $64.1 \pm 3.1 \mathrm{~mm}$, respectively). The stone crabs were maintained on a 12 hour light/dark cycle and starved for 48 hours prior to the beginning of the experiment. Oysters were collected around Morehead City, NC and sorted into two groups: fouled or non-fouled by boring sponge. Oysters of similar sizes (mean \pm st. error: $5.07 \pm 0.07 \mathrm{~cm}$ ) were used to generate 5 oyster density treatments of $1,2,4,8$, and 22 oysters crossed with two sponge treatments (sponge and no sponge). Oysters were added to each stone crab tank at noon on the day of the experiment. Temperature was recorded in an unused tank at the start of each trial $\left(28.4,27.7,25.4\right.$, and $24.3^{\circ} \mathrm{C}$, for trials $1,2,3$, and 4 respectively). The number of oysters eaten was recorded via visual surveys after 24 hours and all remaining oysters were removed.

Following each trial, each crab was then fed two oysters a day for three days after which any non-consumed oysters were removed and the crabs were again starved for 48 hours and rerandomized for use in another replicate. While not ideal, methods for reusing stone crabs through feeding standardization between trials has been previously reported (Wong et al. 2010). In lieu of using new stone crabs for each trial as has been done in previous studies, by using the same crabs, each was influenced by the same background environment before each trial. Additionally, 
102 a previous study with rock crabs (Cancer irroratus) showed reused crabs had no change in 103 mussel capture behavior over a three month holding period (Matheson \& Gagnon 2012). To 104 ensure that any uncertainty due to individuals differences among crabs were accounted for we 105 randomly assigned each crab to a sponge $\mathrm{x}$ density treatment for each trial. This distributed any individual crab effect randomly across treatments which minimizes biases in model fits. Two crabs that never consumed oysters in the lab were replaced by new wild-caught crabs for trials. This experiment was replicated four times and oyster collections were made each week to ensure survival of oysters throughout the experiment. Specifically, we fit a Type II functional response curve using Rogers random predation model

112 (Juliano 2001; Rogers 1972) to quantify predation rates for oysters with and without boring 113 sponge. We used Roger's formulation because it corrects for prey depletion that occurs as a

114 result of predation over the course of the experiment. The random predator model predicts the 115 number of prey eaten, $\mathrm{N}$, as:

$116 N=N_{0}\left(1-e^{-\alpha(T-h N)}\right)$

117 where $T$ is time, $N_{0}$ is the initial prey abundance, $h$ is time spent handling prey and $a$ is the 118 instantaneous attack rate. Rogers equation can be solved iteratively (Juliano 2001) as expressed 119 in equation 1 , however we fit our data to a closed-form solution by expressing equation 1 in 120 terms of Lambert's W function (Bolker 2008; McCoy \& Bolker 2008) so that the number of prey 121 eaten, $\mathrm{N}$, equals:

$122 \quad N=N_{0}-\frac{W\left(\alpha h N_{0} e^{-\alpha\left(T-h N_{0}\right)}\right)}{\alpha h}$ 
124 \& R Development Core Team 2016) with a binomial error distribution. Specifically, we used a

125 flexible parameter approach to fit 1) a model that estimated attack rates and handling times for

126 the two prey types independently (i.e. a 4 parameter model), which tests the hypothesis that

127 sponges affect both the attack rate and handling times of the prey; 2) a single estimate of attack

128 rate, but separate estimates of handling times (for fouled and non-fouled) (3 parameter model),

129 which test the hypothesis that sponges affect the interaction strength by facilitating crab feeding

130 rates; 3) a model that permitted separate estimates of attack rates (for fouled and non-fouled), but

131 only a single estimate of handling time (3 parameter model), which test the hypothesis that

132 sponges change the likelihood of attack by crabs, and 4) a completely random model that fits

133 only a single estimate of attack rate and handling time ( 2 parameter model), which serves as our

134 null model. We did not directly measure attack rate or handling time, consequently these

135 parameters were completely estimated from the model. Model fits and inferences about the

136 effects of boring sponges on the interaction between crabs and oysters were made based on

137 sample size-corrected Akaike Information Criterion (AICc).

\section{Results}

There was similar support for models 1 and 2 (Table 1), which is interesting given that

140 both of these models allow separate estimates of handling times for crabs eating oysters with and

141 without sponges. This may suggest that sponges are having the largest impacts on crab handling

142 times, which is consistent with previous work indicating that boring sponges weakened mollusks

143 shells (Duckworth \& Peterson 2013). Indeed, handling times (and therefore maximum

144 consumption rates) were approximately 280\% longer according to model 1 and 180\% longer

145 according to model 2 for crabs eating oysters without sponges relative to oysters with sponges 
146 (Table 1). However, the most supported model (model 1in Table 1) also includes separate

147 estimates of attack rates on oysters with and without boring sponges. While there is no evidence

148 that Cliona sp. are unpalatable (Guida 1976), lower attack rates on fouled oysters may suggest

149 stone crabs have a higher propensity to attack and consume unfouled oysters. Regardless, the

150 differences in attack rates were offset by longer handling times resulting in overall higher

151 consumption of oysters in sponge treatments than in no sponge treatments (Figure 1).

152 Discussion

153 We investigated how a fouling species that has expanded its range may be indirectly

154 impacting the eastern oyster. Our results show that the presence of fouling from boring sponges

155 will make oysters more susceptible to predation by crabs and likely other shell-crushing

156 predators. One potential mechanism that we present here, is a decrease in predator handling time

157 for oysters with sponges compared to those without sponges. Indeed, boring sponges (Cliona

158 celata) have been shown to weaken scallop shells by as much as $28 \%$ (Duckworth \& Peterson

159 2013). However, other studies have suggested that infestation by boring sponges did not impact

160 stone crab handling times (Coleman 2014). However, this difference may due in part to

161 difference in the sizes of the stone crabs used in the two studies (mean carapace from Coleman

$1622014=98.5$ and current study $64.1 \mathrm{~mm}$ ), such that defenses in shell strength were only evident

163 for smaller crabs.

164 Understanding the potential effects of changes in species ranges and interactions are

165 especially important for foundation species that provide structure that serves as primary habitat

166 for communities of other species (Dayton 1973). Specifically, global environmental change can

167 facilitate species range expansions and alter local trophic interactions (Walther et al. 2002),

168 which is critical information for mitigating and managing affected ecosystems. Boring sponges, 
169 Cliona spp., are experiencing range expansions potentially as a result of increased salinization of

170 some estuarine ecosystems (Dunn et al. 2014; Lindquist 2011). Boring sponge are generally

171 found in areas with >15 ppt salinity (Carver et al. 2010; Hopkins 1962; Lindquist 2011), and

172 they are being documented in increasing abundances further up-estuary as sea level and salinity

173 rise (Hong \& Shen 2012; Lindquist 2011).

174 Therefore, changes in the range of a fouling species in response to changes in habitat

175 characteristics or climate change can have indirect consequences on the trophic interactions

176 between important species (such as oysters and corals) and their natural enemies. Indeed, studies

177 have shown that boring sponges are not impacted by high water temperatures or decreases in $\mathrm{pH}$

178 (due to an increase in atmospheric $\mathrm{CO}_{2}$ ) but instead these factors increase shell boring rates

179 (Duckworth \& Peterson 2013). In addition, documented increases in stone crab northward

180 expansion along with boring sponges, could enhance potential negative impacts to oyster

181 fisheries in states such as Virginia and North Carolina. Overall, understanding how increases in 182 predation risk as a result of fouling by boring sponges works in concert with other effects of

183 global climate change (i.e. sea level rise, ocean acidification and increasing salinity) will have

184 important implications for managing foundation species and the services they provide through

185 fisheries, coastal protection, and ecosystem engineering.

186 This study highlights the need to consider how indirect biotic interactions can alter the

187 interaction strengths between predators and prey. Indeed, boring sponges alone have modest

188 impacts on oyster fitness. However, changes in the distribution and abundance of sponges,

189 increases in boring efficiency, and the interactions between boring sponge and other species can

190 lead to strong negative impacts on oysters and oyster reef communities. Such context dependent 
191 and indirect effects must be considered in future restoration and management aimed at

192 recovering already heavily damaged oyster reef ecosystems (Beck et al. 2011; D'Anna 2016).

193 Acknowledgements

194 We would like to thank Brian Silliman, the members of the Silliman Lab at the Duke

195 Marine Lab, and lab assistants Thomas Guryan and Erin Tomaras for providing lab space and

196 experimental assistance. In addition, we would like to thank David Kimmel, April Blakeslee,

197 Krista McCoy, and the McCoy Labs for constructive comments on this research.

198 References

199 Beck MW, Brumbaugh RD, Airoldi L, Carranza A, Coen LD, Crawford C, Defeo O, Edgar GJ,

200 Hancock B, and Kay MC. 2011. Oyster reefs at risk and recommendations for

201 conservation, restoration, and management. Bioscience 61:107-116.

202 Bolker B, and R Development Core Team. 2016. bbmle: Tools for General Maximum

203 Likelihood Estimation. R package version 1.0.18.

204 Bolker BM. 2008. Ecological models and data in R: Princeton University Press.

205 Carroll JM, Shaughnessy KA, Diedrich GA, and Finelli CM. 2015. Are oysters being bored to

206 death? Influence of Cliona celata on Crassostrea virginica condition, growth and survival.

207 Diseases of aquatic organisms 117:31-44.

208 Carver CE, Thériault I, and Mallet AL. 2010. Infection of cultured eastern oysters Crassostrea

209 virginica by the boring sponge Cliona celata, with emphasis on sponge life history and mitigation strategies. Journal of Shellfish Research 29:905-915.

211

D'Anna LM. 2016. Concern is in the Eye of the Stakeholder: Heterogeneous Assessments of the Threats to Oyster Survival and Restoration in North Carolina. Society \& Natural Resources 29:131-147. 
214 Dayton PK. 1973. Toward an understanding of community resilience and the potential effects of

215

216

217

218

219

220

221

222

223

224

225

226

227

228

229

230

231

232

233

234

235

236

enrichments to the benthos at McMurdo Sound, Antarctica: In: Parker BC (Ed).

Proceedings of the colloquium on conservation problems in Antarctica. Lawrence, KS:

Allen Press.

Duckworth A, and Peterson B. 2013. Effects of seawater temperature and $\mathrm{pH}$ on the boring rates of the sponge Cliona celata in scallop shells. Marine Biology 160:27-35. 10.1007/s00227012-2053-Z

Dunn RP, Eggleston DB, and Lindquist N. 2014. Oyster-sponge interactions and bioerosion of reef-building substrate materials: implications for oyster restoration. Journal of Shellfish Research 33:727-738.

Fang JK, Mello-Athayde MA, Schönberg CH, Kline DI, Hoegh-Guldberg O, and Dove S. 2013. Sponge biomass and bioerosion rates increase under ocean warming and acidification. Global Change Biology 19:3581-3591.

Gilman SE, Urban MC, Tewksbury J, Gilchrist GW, and Holt RD. 2010. A framework for community interactions under climate change. Trends in Ecology \& Evolution 25:325331.

Grabowski JH. 2004. Habitat complexity disrupts predator-prey interactions but not the trophic cascade on oyster reefs. Ecology 85:995-1004.

Guida VG. 1976. Sponge predation in the oyster reef community as demonstrated with Cliona celata Grant. Journal of Experimental Marine Biology and Ecology 25:109-122.

Gutiérrez JL, Jones CG, Strayer DL, and Iribarne OO. 2003. Mollusks as ecosystem engineers: the role of shell production in aquatic habitats. Oikos 101:79-90. 10.1034/j.16000706.2003.12322.x 
237 Hoegh-Guldberg O, Mumby PJ, Hooten AJ, Steneck RS, Greenfield P, Gomez E, Harvell CD,

238 Sale PF, Edwards AJ, and Caldeira K. 2007. Coral reefs under rapid climate change and ocean acidification. Science 318:1737-1742.

Hong B, and Shen J. 2012. Responses of estuarine salinity and transport processes to potential future sea-level rise in the Chesapeake Bay. Estuarine, Coastal and Shelf Science 104:3345.

Hopkins SH. 1962. Distribution of species ofCliona (boring sponge) on the Eastern Shore of Virginia in relation to salinity. Chesapeake Science 3:121-124.

Juliano S. 2001. Nonlinear curve fitting: predation and functional response curves. Design and analysis of ecological experiments 2:178-196.

Kordas RL, Harley CD, and O'Connor MI. 2011. Community ecology in a warming world: the influence of temperature on interspecific interactions in marine systems. Journal of Experimental Marine Biology and Ecology 400:218-226.

Laudien J, and Wahl M. 1999. Indirect effects of epibiosis on host mortality: seastar predation on differently fouled mussels. Marine Ecology 20:35-47.

Lindquist N. 2011. Quantifying boring sponge abundance, biomass and bioerosion rates in North Carolina oyster reefs. North Carolina Sea Grant Fishery Resource Grant Final Report.

Matheson K, and Gagnon P. 2012. Temperature mediates non-competitive foraging in indigenous rock (Cancer irroratus Say) and recently introduced green (Carcinus maenas L.) crabs from Newfoundland and Labrador. Journal of Experimental Marine Biology and Ecology 414:6-18.

McCoy MW, and Bolker BM. 2008. Trait-mediated interactions: influence of prey size, density and experience. Journal of animal ecology 77:478-486. 
260 Menge BA. 1995. Indirect effects in marine rocky intertidal interaction webs: patterns and importance. Ecological Monographs 65:21-74.

262

263

264

265

266

267

268

269

270

271

272

273

274

275

276

277

278

279

280 oyster cultch for intertidal marsh. Restoration Ecology 5:93-99.

Newell RI. 2004. Ecosystem influences of natural and cultivated populations of suspensionfeeding bivalve molluscs: a review. Journal of Shellfish Research 23:51-62.

Preisser EL, Bolnick DI, and Benard MF. 2005. Scared to death? The effects of intimidation and consumption in predator-prey interactions. Ecology 86:501-509.

R Core Team. 2016. R: a language and environment for statistical computing. Vienna, Austria: R Foundation for Statistical Computing.

Rindone RR, and Eggleston DB. 2011. Predator-prey dynamics between recently established stone crabs (Menippe spp.) and oyster prey (Crassostrea virginica). Journal of Experimental Marine Biology and Ecology 407:216-225.

Rogers D. 1972. Random search and insect population models. The Journal of Animal Ecology:369-383.

Schmitt RJ, Osenberg CW, and Bercovitch MG. 1983. Mechanisms and consequences of shell fouling in the kelp snail, Norrisia norrisi (Sowerby)(Trochidae): indirect effects of octopus drilling. Journal of Experimental Marine Biology and Ecology 69:267-281.

Sorte CJ, Williams SL, and Carlton JT. 2010. Marine range shifts and species introductions: comparative spread rates and community impacts. Global Ecology and Biogeography 19:303-316. 
281 Stefaniak LM, McAtee J, and Shulman MJ. 2005. The costs of being bored: effects of a clionid

282

283

284

285

286

287

288

289

290

291

292

293

294

295

296

297

298

299

300

301 sponge on the gastropod Littorina littorea (L). Journal of Experimental Marine Biology and Ecology 327:103-114.

Sunday JM, Fabricius KE, Kroeker KJ, Anderson KM, Brown NE, Barry JP, Connell SD, Dupont S, Gaylord B, and Hall-Spencer JM. 2016. Ocean acidification can mediate biodiversity shifts by changing biogenic habitat. Nature Climate Change.

van Wesenbeeck BK, Griffin JN, van Koningsveld M, Gedan KB, McCoy MW, and Silliman BR. 2013. Nature-Based Coastal Defenses: Can Biodiversity Help? In: Levin S, ed. Encyclopedia of Biodiversity. Waltham, MA: Academic Press, 451-458.

Wahl M, Hay M, and Enderlein P. 1997. Effects of epibiosis on consumer-prey interactions. Hydrobiologia 355:49-59.

Walther G-R. 2010. Community and ecosystem responses to recent climate change. Philosophical Transactions of the Royal Society B: Biological Sciences 365:2019-2024.

Walther G-R, Post E, Convey P, Menzel A, Parmesan C, Beebee TJ, Fromentin J-M, HoeghGuldberg O, and Bairlein F. 2002. Ecological responses to recent climate change. Nature 416:389-395.

Werner EE, and Peacor SD. 2003. A review of trait-mediated indirect interactions in ecological communities. Ecology 84:1083-1100.

Wong MC, Peterson CH, and Kay J. 2010. Prey size selection and bottom type influence multiple predator effects in a crab-bivalve system. Marine Ecology Progress Series 409:143-156. 


\section{Table $\mathbf{1}$ (on next page)}

Maximum likelihood results

AICc values for each model. Estimates are presented for all parameters ( $\alpha=$ attack rate and $h=$ handling time) allowed to vary by treatment in a model (95\% confidence intervals are presented underneath each estimate). With few observations (nobs $=38$ ), corrected AIC (AICC) was used instead of AIC. 
1

\begin{tabular}{|c|c|c|c|c|c|c|c|c|c|c|}
\hline \multirow{2}{*}{ Model } & \multirow{2}{*}{ Parameters } & \multirow{2}{*}{ dAICc } & \multirow{2}{*}{ df } & \multirow{2}{*}{ weight } & \multicolumn{3}{|c|}{$\alpha$} & \multicolumn{3}{|c|}{$h$} \\
\hline & & & & & No Sponge & & Sponge & No Sponge & & Sponge \\
\hline 1 & $a * h$ & 0 & 4 & 0.597 & $\begin{array}{c}4.079 \\
(1.457,6.701)\end{array}$ & & $\begin{array}{c}1.970 \\
(-3.416,7.357)\end{array}$ & $\begin{array}{c}0.112 \\
(0.075,0.149)\end{array}$ & & $\begin{array}{c}0.039 \\
(-0.043,0.123)\end{array}$ \\
\hline 2 & $\mathrm{~h}$ & 1.1 & 3 & 0.352 & & $\begin{array}{c}2.534 \\
(1.660,3.408)\end{array}$ & & $\begin{array}{c}0.093 \\
(0.063,0.123)\end{array}$ & & $\begin{array}{c}0.051 \\
(-0.011,0.113)\end{array}$ \\
\hline 3 & $\mathrm{a}$ & 5.5 & 2 & 0.038 & $\begin{array}{c}2.414 \\
(1.140,3.688)\end{array}$ & & $\begin{array}{c}1.97 \\
(0.060,5.353)\end{array}$ & & $\begin{array}{c}0.072 \\
(0.048,0.095)\end{array}$ & \\
\hline 4 & 1 & 7.7 & 3 & 0.013 & & $\begin{array}{c}2.62 \\
(1.690,3.551) \\
\end{array}$ & & & $\begin{array}{c}0.074 \\
(0.052,0.096) \\
\end{array}$ & \\
\hline
\end{tabular}

2 
Figure 1 (on next page)

Prey Consumed Over 24 Hours

Amount of prey consumed by predators over a 24 hour period using five increasing densities. Lines represent oysters (Crassostrea virginica) with sponges (Cliona spp.) (black) and oysters without sponges (gray), with standard error bars for each point ( $n=4$ trials). Attack rates and handling times used for each line were obtained from model 1 (see Table 1). 


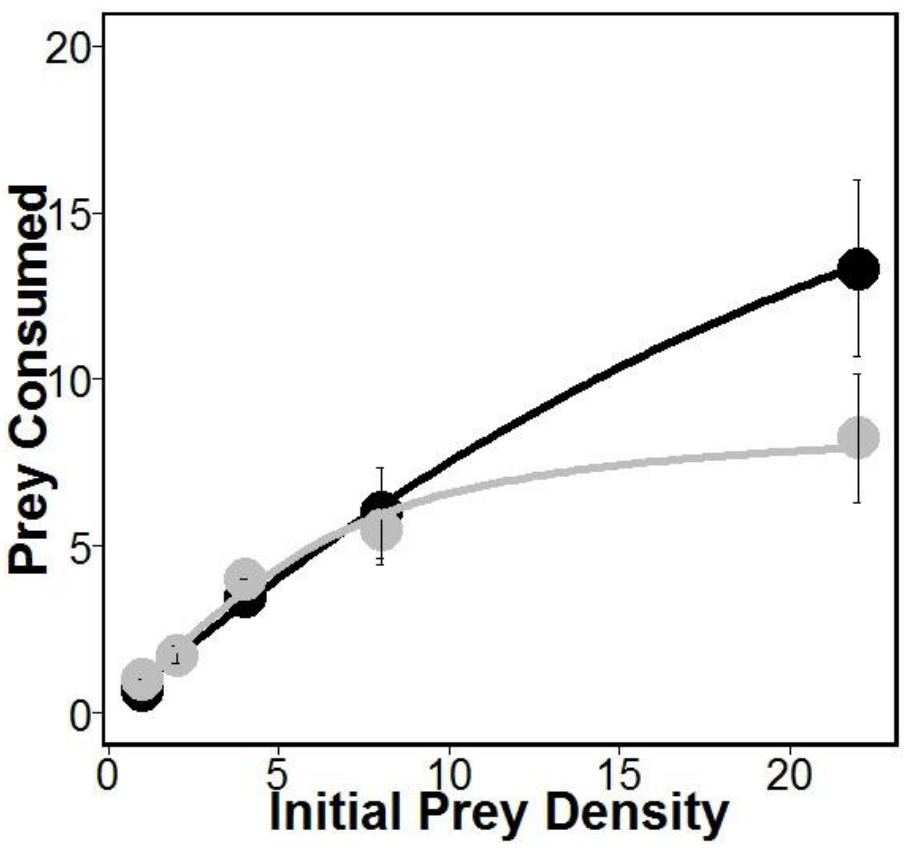

1

2 